\title{
Increased expression of miR-221 is associated with shorter overall survival in T-cell acute lymphoid leukemia
}

\author{
Hamilton L Gimenes-Teixeira' ${ }^{1}$, Antonio R Lucena-Araujo ${ }^{1}$, Guilherme A dos Santos', Dalila L Zanette², \\ Priscila S Scheucher ${ }^{1}$, Luciana C Oliveira ${ }^{1}$, Leandro F Dalmazzo ${ }^{1}$, Wilson A Silva-Júnior ${ }^{2}$, Roberto P Falcão \\ and Eduardo M Rego ${ }^{1,3^{*}}$
}

\begin{abstract}
Background: CD56 expression has been associated with a poor prognosis in lymphoid neoplasms, including T-cell acute lymphoblastic leukemia (T-ALL). MicroRNAs (miRNAs) play an important role in lymphoid differentiation, and aberrant miRNA expression has been associated with treatment outcome in lymphoid malignancies. Here, we evaluated miRNA expression profiles in normal thymocytes, mature T-cells, and T-ALL samples with and without CD56 expression and correlated microRNA expression with treatment outcome.

Methods: The gene expression profile of 164 miRNAs were compared for T-ALL/CD56 ${ }^{+}(n=12)$ and T-ALL/CD56 $(n=36)$ patients by Real-Time Quantitative PCR. Based on this analysis, we decided to evaluate miR-221 and miR-374 expression in individual leukemic and normal samples.

Results: miR-221 and miR-374 were expressed at significantly higher levels in T-ALL/CD56 ${ }^{+}$than in T-ALL/CD56 cells and in leukemic blasts compared with normal thymocytes and peripheral blood (PB) T-cells. Age at diagnosis (15 or less vs grater than 15 years; HR: 2.19, 95\% Cl: 0.98-4.85; $P=0.05$ ), miR-221 expression level (median value as cut off in leukemic samples; HR: 3.17, 95\% Cl: 1.45-6.92; $P=0.004$ ), and the expression of CD56 (CD56 vs CD56 ${ }^{+}$; HR: 2.99, 95\% Cl: 1.37-6.51; $P=0.006$ ) were predictive factors for shorter overall survival; whereas, only CD56 expression (HR: $2.73,95 \% \mathrm{Cl}: 1.03-7.18 ; P=0.041$ ) was associated with a shorter disease-free survival rate.
\end{abstract}

Conclusions: miR-221 is highly expressed in T-ALL and its expression level may be associated with a poorer prognosis.

Keywords: T-cell acute lymphoid leukemia, miRNA, CD56, Treatment outcome

\section{Background}

Neural-cell adhesion molecule (N-CAM; CD56) is a known marker of natural killer (NK) cells [1]. The two best characterized forms of NK-cell malignancy are the aggressive NK-cell leukemia (ANKL) and the extra nodal NK-cell lymphoma, nasal type (ENKL) [2,3]. However, CD56 is also expressed on a subset of normal $\mathrm{T}$ cells and occasionally on blasts in T-cell acute lymphoblastic leukemia (T-ALL) [4]. The expression status of CD56

\footnotetext{
* Correspondence: emrego@hcrp.fmrp.usp.br

${ }^{1}$ Department of Internal Medicine, Division of Hematology/Oncology,

University of São Paulo, Ribeirão Preto, Brazil

${ }^{3}$ Medical School of Ribeirao Preto, University of São Paulo, Av. Bandeirantes, 3900, Ribeirao Preto, SP 14048-900, Brazil

Full list of author information is available at the end of the article
}

identified a subgroup of patients with T-ALL who did not respond well to therapy $[4,5]$. From an ontogenetic point of view, NK cells arise from T/NK bi-potential common progenitors [6,7]; therefore, NK-cells are functionally and phenotypically very similar to T-cells, particularly cytotoxic T-cells.

MicroRNAs (miRNAs) play an important role in lymphoid differentiation and in innate immune response [8-10], and aberrant miRNA expression has been associated with treatment outcome in hematological malignancies [11-13]. Wang et al. demonstrated that miR-378 and miR-30e are suppressors of NK cell cytotoxicity and their expression is regulated by IFN $\alpha$ [14]. Furthermore, Chiaretti et al. recently described a large set of myeloid-

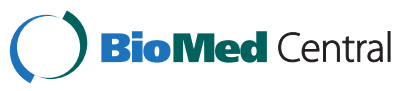


related miRNAs overexpressed in a subset of adult T-ALL patients; interestingly, the "myeloid-like" cases presented with higher expression levels of miR-223 and poorer prognoses compared with T-ALL patients without overexpression of myeloid-related genes [15].

Some miRNAs may be relevant in T-ALL leukemogenesis. Mavrakis et al. identified five miRNAs (miR-19b, miR-20a, miR-26a, miR-92, and miR-223) in a human T-ALL library that were capable of promoting T-ALL development in a mouse model [16]. Moreover, these miRNAs acted synergistically with tumor suppressor genes implicated in the pathogenesis of T-ALL [16]. In the present study, we compared expression of 164 miRNAs in T-ALL blasts with and without CD56 expression and correlated these profiles with T-cell development and treatment outcome.

\section{Results and discussion}

Initially, we identified 56 miRNAs with higher expression and 35 with lower expression levels in the T-ALL/ $\mathrm{CD}^{+} 6^{+}$group compared with the T-ALL/CD56 group (Additional file 1: Table S1). Expression of miR-221 and
miR-374 were higher in T-ALL/CD56 ${ }^{+}$compared with T-ALL/CD56 cells, with 271- and 181-fold changes, respectively, and were chosen for further analyses. Irrespective of CD56 expression, miR-221 (Figure 1A) and miR-374 (Figure 1B) expression were higher in leukemic blasts compared with normal peripheral blood (PB) T-cells and thymocytes. By adopting the upper limits of the $95 \%$ confidence intervals of miR-221 and miR-374 expression in the normal $\mathrm{T} / \mathrm{CD}^{+}{ }^{+}$samples as cut-offs, $48 / 48$ (100\%) and $38 / 47$ (81\%) of the T-ALL samples, respectively, had expression higher than the cut-off values.

We did not detect differences in miR-221 and miR374 expression when comparing triple positive thymocytes $\left(\mathrm{CD}^{+} / \mathrm{CD}^{+} / \mathrm{CD}^{+}\right)$and mature T-cells in $\mathrm{PB}$ of healthy subjects. Our results do not corroborate the study by Kirigin et al. [8], which analyzed miRNAs in different stages of $\mathrm{T}$-cell differentiation in the murine thymus and bone marrow using next generation sequencing. The authors demonstrated that there was greater expression of miR-221 and miR-222 in early stages compared with mature thymocytes. However, the comparison between the two studies must be regarded with

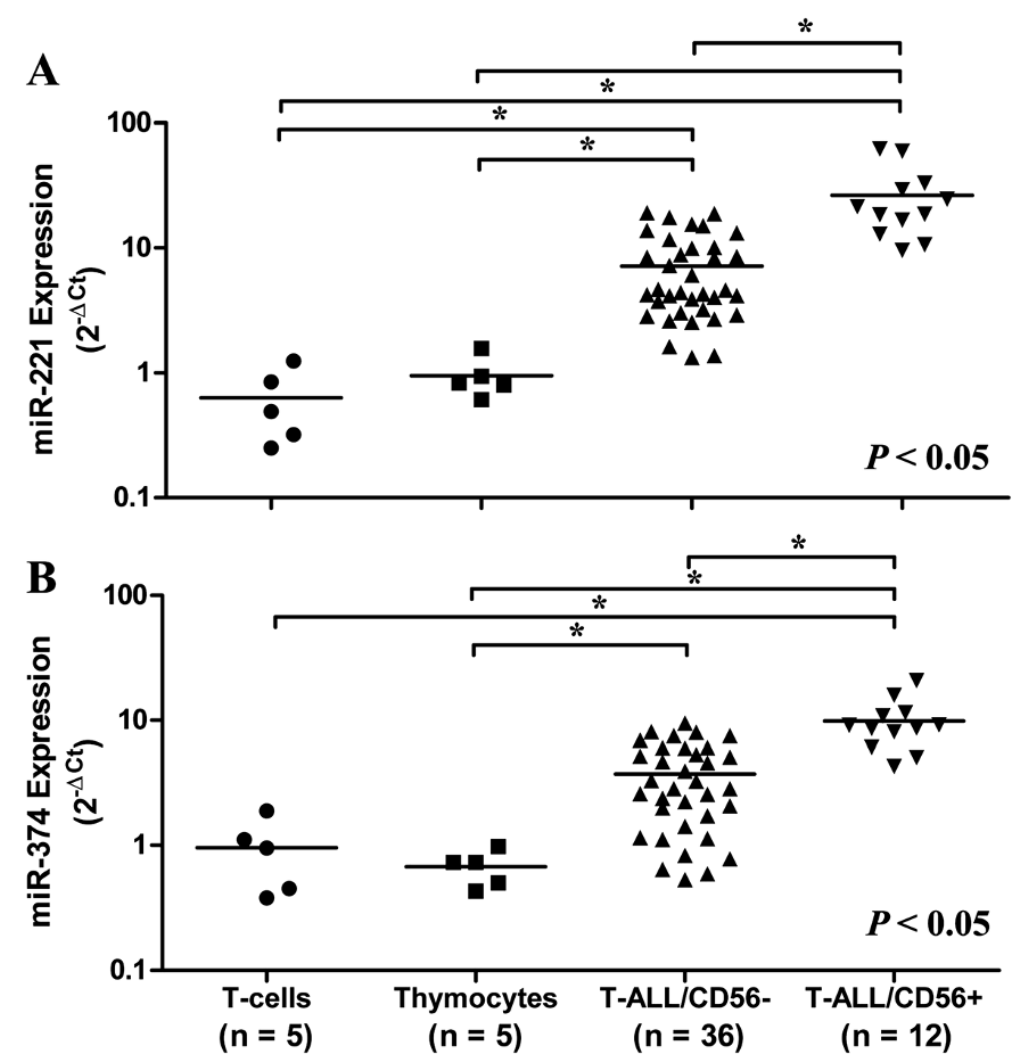

Figure 1 Quantitative analysis of miR-221 (A) and miR-374 (B) expression in samples from T-ALL patients, T-cells from normal peripheral blood, and $\mathrm{CD}^{+} / \mathrm{CD}^{+} / \mathrm{CD}^{+}$thymocytes. Leukemic samples from $48 \mathrm{~T}$-ALL patients were obtained from cell banks. The expression of miRNAs was quantified by Real-Time Quantitative PCR (RQ-PCR). The horizontal bars represent the mean of miRNA expression calculated by $2^{-\Delta C t}$. T-ALL samples were categorized according to presence of the CD56 cell marker: 12 samples were positive (T-ALL/CD56 ${ }^{+}$) and 36 were negative (T-ALL/CD56). Asterisks indicate significant differences between groups (ANOVA test followed by a Dunn's post-test). 
caution because Kirigin et al. [8] have used a more complex strategy of cell sorting, and analyzed T-cell subsets that do not completely overlap with those of our study. The double positive (DP) thymocytes in their study had the immunophenotype $\mathrm{CD} 90^{+} \mathrm{CD} 4^{+} \mathrm{CD} 8^{+} \mathrm{CD} 3^{\text {low }}$ and were compared with $\mathrm{CD} 4$ single positive (SP) $\left(\mathrm{CD} 90^{+}\right.$ $\left.\mathrm{CD} 4{ }^{+} \mathrm{CD} 8{ }^{-} \mathrm{CD} 24^{\text {low }}{ }^{\mathrm{CD}} 3^{\text {high }}\right)$, and $\mathrm{CD} 8 \mathrm{SP}\left(\mathrm{CD} 90^{+} \mathrm{CD} 42\right.$ $\left.\mathrm{CD} 8{ }^{+} \mathrm{CD} 24^{\text {low }}{ }^{\mathrm{CD}} 3^{\text {high }}\right)$ subsets. In addition, the most significant difference in miR-221 expression demonstrated by Kirigin et al. [8] was between double negative four (DN4, CD90 ${ }^{+} \mathrm{CD} 44^{-} \mathrm{CD} 8^{-} \mathrm{CD} 3^{\text {low }} \mathrm{CD} 44^{-} \mathrm{CD} 25^{-}$) thymocytes and CD4SP and CD8SP mature T-cells [8], and such analysis was not performed in the present study.

miR-221 is up-regulated in several human malignancies; whereas, there are few reports associating miR-374 with tumorigenesis. Nevertheless, the mechanisms leading to the higher expression of these miRNAs are unknown. Recently, Santhekadur et al. [17] demonstrated that RNA Induced Silencing Complex (RISC) proteins SND1 and AEG-1 induce miR-221 expression in a NFkB dependent way in liver cancer cells. An alternative explanation would be that extracellular stimuli may interfere with miRNAs expression. With this regard, Davis et al. [18] demonstrated that miR-221 is a mediator of Platelet Derived
Growth Factor (PDGF) signaling through modulation of p2 $7^{\text {Kip1 }}$. Remarkably, high levels of PGDF signaling were described as a decisive factor for proliferation and survival in cytotoxic $\mathrm{T}$ and natural killer cell neoplasms [19].

The transcription factor BCL11B has been identified as a putative target of miR-221 and it has been previously demonstrated that BCL11B expression is required to repress natural killer cell-associated genes and essential for $\mathrm{T}$ lineage commitment [20-22]. Overexpression of BCL11B was reported in T-ALL [23] and in adult T-cell leukemia/lymphoma [24] and its silencing in Molt-4 cells was associated with increased expression of the antiapoptotic protein Bcl-2 [20]. Previously reported miR-221 targets include the cell cycle regulators CDKN1B/p27 ${ }^{\text {Kip1 }}$ and CDKN1C/p57 ${ }^{\text {Kip2 } 2 \text { [25-27]. Le Sage }}$ et al. [25] demonstrated that cancer cell lines require high expression of miR-221/222 to maintain low p2 $7^{\text {kip } 1}$ levels and continuous proliferation. Therefore, it is conceivable that miR-221 acts as an oncogene through inhibition of $\mathrm{p} 27^{\mathrm{kip} 1}$ in T-ALL. Another known target of miR-221 is the receptor c-KIT. Fellicetti et al. [28] showed an inverse correlation between miR-221 and miR-222 expression and c-KIT protein levels during melanoma progression. In addition, c-KIT is rapidly up-regulated following NOTCH

Table 1 Clinical and immunophenotypic features of T-ALL patients at diagnosis according to expression of miR-221 and miR-374

\begin{tabular}{|c|c|c|c|c|c|c|}
\hline \multirow{2}{*}{$\begin{array}{l}\text { Patient } \\
\text { characteristics }\end{array}$} & \multicolumn{2}{|c|}{ miR-221 } & \multirow[b]{2}{*}{$P$-value } & \multicolumn{2}{|c|}{ miR-374 } & \multirow[b]{2}{*}{$P$-value } \\
\hline & High expression & Low expression & & High expression & Low expression & \\
\hline Age $^{1}$, years & $22.8(1-66)$ & $17.4(2-44)$ & 0.22 & $23.6(1-66)$ & $16.8(2-44)$ & 0.49 \\
\hline Gender (M/F) & $24(18 / 6)$ & $24(21 / 3)$ & 0.46 & $24(21 / 3)$ & $23(17 / 6)$ & 0.12 \\
\hline Mediastinal mass (\%) & $14 / 24(58)$ & $6 / 24(25)$ & 0.15 & $15 / 24(62.5)$ & $5 / 23(22)$ & 0.13 \\
\hline Lymphadenopathy (\%) & $15 / 24(62.5)$ & $21 / 24(87.5)$ & 0.26 & $16 / 24(67)$ & 19/23(83) & 0.24 \\
\hline Splenomegaly (\%) & $16 / 24(67)$ & $16 / 24(67)$ & 0.66 & $17 / 24(71)$ & $14 / 23(61)$ & 0.6 \\
\hline Hepatomegaly (\%) & $15 / 24(62.5)$ & $16 / 24(67)$ & 0.99 & $17 / 24(71)$ & $13 / 23(56.5)$ & 0.44 \\
\hline CNS involvement (\%) & $1 / 24(4)$ & $2 / 24(8)$ & 0.56 & $2 / 24(8)$ & $1 / 23(4)$ & 0.53 \\
\hline Blasts BM $\mathrm{BM}^{1}(\%)$ & $77.3(20-100)$ & $90.5(28-100)$ & 0.09 & $77.6(20-100)$ & $90.7(28-100)$ & 0.64 \\
\hline Blasts PB ${ }^{1}(\%)$ & $63.4(0-100)$ & $78.5(10-100)$ & 0.18 & $61.5(0-100)$ & $86(10-100)$ & 0.45 \\
\hline Hemoglobin ${ }^{1}(g / l)$ & $10.4(3.6-15.6)$ & $10.4(4.6-17.1)$ & 0.97 & $10.1(3.6-15.8)$ & $10.8(5.3-17.1)$ & 0.4 \\
\hline WBC $^{1}$ count $\times 10^{9} / \mathrm{l}$ & $104(4.6-314)$ & $202.3(4.5-790)$ & 0.06 & $118(4.5-781)$ & $196(18-789)$ & 0.61 \\
\hline Platelets $^{1} \times 10^{9} / \mathrm{l}$ & $149.4(9-652)$ & $48.8(9-185)$ & $0.009^{*}$ & $140(9-652)$ & $55.8(9-231)$ & $0.03^{*}$ \\
\hline Pre thymic (\%) & $7 / 24(29)$ & $4 / 24(17)$ & 0.31 & $6 / 24(25)$ & $5 / 23(22)$ & 0.81 \\
\hline Thymic (\%) & $7 / 24(29)$ & $10 / 24(42)$ & 0.54 & $9 / 24(37.5)$ & 7/23(30) & 0.51 \\
\hline Mature T (\%) & $8 / 24(33)$ & $8 / 24(33)$ & 0.98 & $7 / 24(29)$ & 9/23(39) & 0.37 \\
\hline CD34 (\%) & $16 / 24(67)$ & $8 / 24(33)$ & $0.042^{*}$ & $13 / 24(54)$ & $11 / 23(48)$ & 0.56 \\
\hline CD56 (\%) & $11 / 24(46)$ & $1 / 24(4)$ & $0.001^{*}$ & $12 / 24(50)$ & $1 / 23(4)$ & $<0.001^{*}$ \\
\hline TdT (\%) & 18/24(75) & $21 / 24(87)$ & 0.46 & $17 / 24(71)$ & 21/23(91) & 0.28 \\
\hline
\end{tabular}

CNS: central nervous system; WBC: white blood cell; PB: peripheral blood; BM: bone marrow; cCD3: cytoplasmic CD3; sCD3: surface CD3; TdT: terminal deoxynucleotidyl transferase. ${ }^{*}$ Significant $P$-value.

${ }^{1}$ Values represent mean (range). 

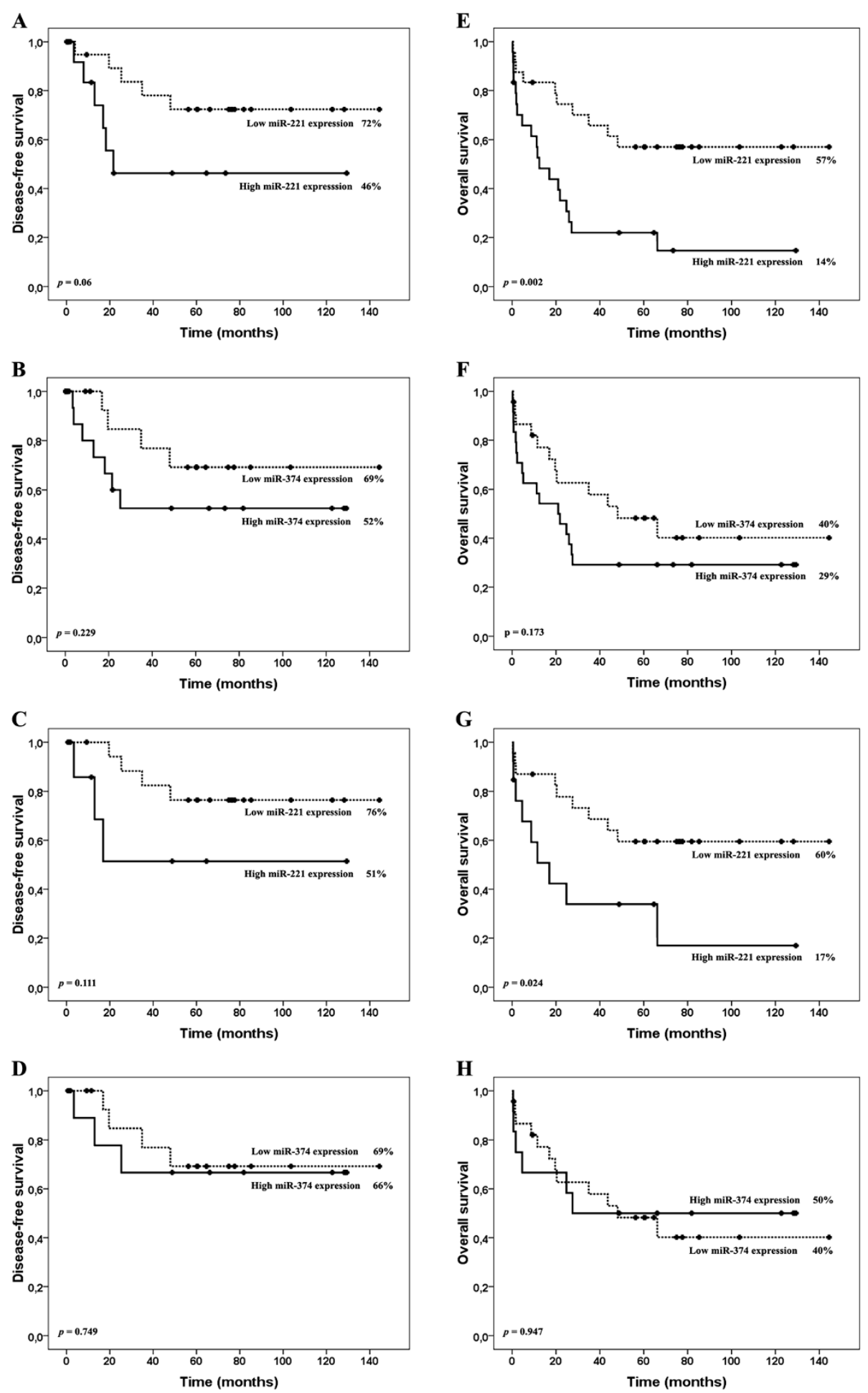

Figure 2 Disease-free survival (2A-2D) and overall survival (2E-2H) in T-ALL patients according to miR-221 and miR-374 expression. $2 \mathbf{A}-2 \mathbf{B}$ and $2 \mathbf{E}-2 \mathbf{F}$ represent analyses in the whole population; whereas, $2 \mathbf{C}-2 \mathbf{D}$ and $2 \mathbf{G}-2 \mathbf{H}$ represent analyses in only T-ALL/CD56 patients. 
signaling in T-cell development, and the development of primitive cells into non T-cell fates (NK or myeloid) was found to be c-kit independent [28].

For the analysis of the relevance of miR-221 and miR374 expression levels in the response to treatment, we arbitrarily divided T-ALL patients in low $(\leq$ median value in all T-ALL samples) or high ( $>$ than the median value) expression groups. The main clinical and laboratory features at diagnosis are summarized in Table 1 . The only significant differences between patients with high versus low expression of miR-221 and miR-374 were higher platelet counts in patients expressing higher levels of miR-221 $(P=0.009)$ and miR-374 $(P=0.03)$ and a higher frequency of $\mathrm{CD} 34^{+}$cases in the group with higher miR-221 expression $(P=0.042)$. The mean follow-up among survivors was 27 months (range, 12 to 42 months). The complete hematological remission (CR) rate for the whole population was $66 \%$ and did not differ between high- and low- miR-221 (54\% versus 79\%; $P=0.125)$ and miR-374 (62\% versus $69 \% ; P=0.76)$ expression groups. In the whole population, high miR-221 patients had a lower disease-free survival (DFS) (46\%) compared with low miR-221 patients $(72 \%, P=0.06$; Figure 2A); while, miR-374 did not impact the DFS (69\% versus $52 \%, P=0.229$; Figure $2 \mathrm{~B}$ ). When the analysis was restricted to T-ALL/CD56 patients, the DFS did not differ between low and high miR-221 (76\% versus 51\%, $P=0.111$; Figure 2 C) and miR-374 groups (69\% versus $66 \%, P=0.749$; Figure 2D).

Patients with high miR-221 expression had significantly lower 5-year OS rates compared with those with low miR221 expression ( $14 \%$ versus $57 \%, P=0.002$; Figure $2 \mathrm{E}$ ). Among T-ALL/CD56 patients, those with higher miR221 expression had lower OS (17\% versus 60\%, $P=0.024$;
Figure 2G). No difference in OS was observed based on miR-374 expression when considering the whole population ( $40 \%$ versus $29 \%$ in low- versus high-miR374 groups, $P=0.173$; Figure $2 \mathrm{~F}$ ) or just T-ALL/CD56 patients ( $40 \%$ versus $50 \%$ in low- versus high-miR374 groups, $P=0.947$; Figure $2 \mathrm{H}$ ). In the univariate analysis, expression of miR-221 (HR: 3.17, 95\% CI: 1.45 to 6.92; $P=0.004$ ), CD56 expression (HR: $2.99,95 \%$ CI: 1.37 to 6.51; $P=0.006$ ), and age (HR: $2.19,95 \%$ CI: 0.98 to 4.85 ; $P=0.05)$ were associated with poorer OS; whereas, only CD56 expression was predictive of poorer DFS (HR: 2.73, 95\% CI: 1.03 to $7.18 ; P=0.041)$. Nonetheless, these factors were not independent after adjustment (Table 2).

We selected the T-ALL/CD56 ${ }^{+}$and CD56 subgroups based on previous studies by Dalmazzo et al. [4] and Fischer et al. [29], which suggest that CD56 identifies a subgroup of patients with distinct immunophenotypic and clinical features, such as higher resistance to therapy and older age. Nevertheless, after risk adapted treatment, the prognostic impact of CD56 expression was not significant in the study by Fisher et al. [29] in contrast to the results reported by Dalmazzo et al. [4]. We must point out that $47 / 48$ (98\%) patients reported here were also included in the study of Dalmazzo et al. [4], although the follow-up data were updated.

Our results suggest that miR-221 may be a useful biomarker in T-ALL. Patients with T-ALL/CD56 with high expression of miR-221, as well as those with T-ALL/ $\mathrm{CD} 56^{+}$presented shorter OS and, therefore may require a more careful monitoring of the response to treatment and/or may be considered candidates to more intensive therapy. However, our conclusions are limited by the sample size and need to be further investigated in a larger cohort.

Table 2 Univariate and multivariate analyses for CR, OS, and DFS in 48 patients with T-ALL

\begin{tabular}{|c|c|c|c|c|c|c|c|c|c|c|c|}
\hline \multirow{3}{*}{$\begin{array}{l}\text { End point } \\
\mathrm{CR}\end{array}$} & \multirow{3}{*}{$\begin{array}{l}\text { Model variables } \\
\text { miR-221 expression (low vs high) }\end{array}$} & \multicolumn{5}{|c|}{ Univariate analysis } & \multicolumn{5}{|c|}{ Multivariate analysis } \\
\hline & & \multirow[t]{2}{*}{$\mathrm{HR}$} & \multirow{2}{*}{$\begin{array}{l}\text { OR } \\
0.63\end{array}$} & \multicolumn{2}{|c|}{$95 \% \mathrm{Cl}$} & \multirow{2}{*}{$\begin{array}{l}\boldsymbol{P} \text {-value } \\
0.507\end{array}$} & \multirow[t]{2}{*}{$\mathrm{HR}$} & \multirow{2}{*}{$\begin{array}{l}\text { OR } \\
1.71\end{array}$} & \multicolumn{2}{|c|}{$95 \% \mathrm{Cl}$} & \multirow{2}{*}{$\begin{array}{l}P \text {-value } \\
0.571\end{array}$} \\
\hline & & & & 0.17 & 2.39 & & & & 0.26 & 10.9 & \\
\hline & WBC counts $\left(\leq 30 \times 10^{9} / \mathrm{L}\right.$ vs $\left.>30 \times 10^{9} / \mathrm{L}\right)$ & & 1.55 & 0.32 & 7.41 & 0.581 & & 0.92 & 0.11 & 7.15 & 0.94 \\
\hline & Age at diagnosis ( $\leq 15$ vs $>15$ ) & & 1.68 & 0.43 & 6.54 & 0.454 & & 2.63 & 0.53 & 12.9 & 0.234 \\
\hline & CD56 expression (CD56 vs CD56 ${ }^{+}$) & & 0.33 & 0.08 & 1.38 & 0.133 & & 0.14 & 0.01 & 1.2 & 0.073 \\
\hline \multirow[t]{4}{*}{ OS } & miR-221 expression (low vs high) & 3.17 & & 1.45 & 6.92 & 0.004 & 2.31 & & 0.92 & 5.81 & 0.074 \\
\hline & WBC counts $\left(\leq 30 \times 10^{9} / \mathrm{L} v s>30 \times 10^{9} / \mathrm{L}\right)$ & 0.69 & & 0.29 & 1.64 & 0.412 & 1.41 & & 0.53 & 3.7 & 0.481 \\
\hline & Age at Diagnosis ( $\leq 15$ vs $>15$ ) & 2.19 & & 0.98 & 4.85 & 0.05 & 2.2 & & 0.96 & 5 & 0.059 \\
\hline & CD56 expression (CD56 vs CD56 ${ }^{+}$) & 2.99 & & 1.37 & 6.51 & 0.006 & 2.04 & & 0.76 & 5.46 & 0.155 \\
\hline \multirow[t]{4}{*}{ DFS } & miR-221 expression (low vs high) & 1.87 & & 0.89 & 3.92 & 0.093 & 1.54 & & 0.57 & 4.17 & 0.391 \\
\hline & WBC counts $\left(\leq 30 \times 10^{9} / \mathrm{L}\right.$ vs $\left.>30 \times 10^{9} / \mathrm{L}\right)$ & 1.76 & & 0.81 & 3.82 & 0.148 & 1.81 & & 0.65 & 5.01 & 0.25 \\
\hline & Age at diagnosis ( $\leq 15$ vs $>15$ ) & 0.77 & & 0.37 & 1.6 & 0.488 & 0.89 & & 0.42 & 1.9 & 0.778 \\
\hline & CD56 expression (CD56 vs CD56 ${ }^{+}$) & 2.73 & & 1.03 & 7.18 & 0.041 & 2.25 & & 0.69 & 7.28 & 0.173 \\
\hline
\end{tabular}




\section{Methods \\ Patients}

Forty-eight bone marrow samples from T-ALL patients were analyzed. All cases were diagnosed in the Hematology Laboratory of the University Hospital of the Medical School of Ribeirão Preto, University of São Paulo from May 1997 to April 2008. The diagnosis of T-ALL was established based on the World Health Organization criteria [30]. Patients were treated according to the HyperCVAD [31] $(\mathrm{n}=6)$, Berlin-Frankfurt-Munich 90 (BFM-90) [32] ( $\mathrm{n}=16$ ), or Brazilian Childhood Leukemia Treatment Group - Acute Lymphoid Leukemia 99 (GBTLI-ALL99) [33] $(\mathrm{n}=20)$ protocols. Six patients were excluded from survival analyses; one patient died before the beginning of treatment and the others five had no clinical data available. This study was approved by the local Ethics Committee (process \#7147/2005).

\section{Purification of thymocytes and peripheral blood T-cells}

Thymic samples were obtained as surgical tissue discards from five pediatric patients (aged 2 days to 5 years) undergoing cardiac surgery at the University Hospital of the Medical School of Ribeirão Preto. Thymocytes were isolated by cutting the thymic lobes into small pieces and forcing them through plastic mesh. Triple positive thymocytes $\left(\mathrm{CD}^{+} / \mathrm{CD}^{+} / \mathrm{CD}^{+}\right)$were purified by immunomagnetic separation (Miltenyi Biotec) after labeling with anti-CD4 and anti-CD8 antibodies, and then passed through a lymphocyte separation column (Miltenyi Biotec, Germany) for the positive selection of labeled cells. After isolation, all samples were more than $95 \%$ pure.

Peripheral blood mononuclear cells (PBMCs) from five healthy donors were harvested by centrifugation on Ficoll-Hypaque (Sigma Aldrich, USA) density gradients, and $\mathrm{PB} \mathrm{T} / \mathrm{CD}^{+}$cells were isolated using magneticactivated cell sorting (MACS; Miltenyi Biotec, Germany), according to the manufacturer's protocol. The homogeneity of $\mathrm{PB} \mathrm{T} / \mathrm{CD}^{+}$cells was confirmed by flow cytometry, and the purity was greater than $85 \%$ in all samples.

\section{Immunophenotyping}

Immunophenotyping of the blasts was performed by flow cytometry. The technique and the panel of fluorochromeconjugated monoclonal antibodies were described previously [4]. We also expanded the panel and analyzed the expression of TdT, CD34, cytoplasmic CD3 (cCD3), surface CD3 (sCD3), CD4, and CD8 in leukemic cells. The minimum threshold for a positive reaction to a given antibody was defined as $20 \%$ of blasts positive for the respective antigen.

RNA extraction and real-time quantitative PCR of miRNAs Total RNA from leukemic samples and healthy donors was isolated using Trizol reagent (Invitrogen, Carlsbad,
CA, USA). Complementary DNA (cDNA) was synthesized from $1 \mu \mathrm{g}$ of total RNA using a High Capacity cDNA reverse transcription Kit (Applied BioSystems, Foster City, CA, USA), following the manufacturer's instructions. The TaqMan ${ }^{\circledR}$ MicroRNA Assays Human Panel (Applied BioSystems, Foster City, CA, USA) was employed to assess the expression levels of 164 miRNAs in leukemic samples. Due to the limited amount of RNA, we pooled the samples according to the immunophenotype (T-ALL/ $\mathrm{CD}^{2} 6^{+}$versus $\mathrm{T}-\mathrm{ALL} / \mathrm{CD} 56^{-}$) and performed a preliminary analysis comparing the two groups. Comparisons with coefficients of variation greater than $5 \%$ were excluded. We defined a strength cut-off for differential expression as $\geq 4$ and $\leq 0.25$. The fold change was calculated using the comparative cycle threshold $(\mathrm{Ct})$ method, in which the geometric mean of expression of RNUs $6 \mathrm{~B}, 19,38 \mathrm{~B}$ and 66 was used for normalization.

Based on this preliminary analysis, we decided to evaluate expression of miR-221 and miR-374 in individual T-ALL, normal thymic, and PB samples. TaqMan-based Real Time Quantitative Polymerase Chain Reaction (RQ-PCR) assays were performed using specific RTstem-looped primers and probes (Applied BioSystems, Foster City, CA, USA). All reactions were carried out in duplicate.

\section{Statistical analysis}

The median values of miR-221 and miR-374 expression in leukemic samples were used as references to classify T-ALL patients into high and low expression groups. Student's $\mathrm{t}$ and Fisher's exact tests were employed to compare differences between the groups. Overall survival (OS) was estimated by the Kaplan-Meier method. Differences among groups were compared by log-rank test. Multivariate regression analysis was performed for OS using the Cox proportional hazards model. All $P$ values were two sided. The level of significance was set at $5 \%$. All the statistical tests were performed using the Statistical Package for the Social Sciences (SPSS) v.17.0 software (SPSS Inc, Chicago, IL, USA) and Stata Statistic/ Data Analysis 9.1 (Stata Corporation, College Station, TX, USA).

\section{Additional file}

Additional file 1: Table S1. Relative expression of miRNAs in T-ALL/

CD56 ${ }^{+}$pooled samples.

Competing interest

The authors declare that they have no competing interest.

Authors' contributions

HLGT, ARLA and GAS performed experiments, analyzed and interpreted data and drafted the article. DLZ and PSS performed experiments and collected data. ARLA and LCO performed the statistical analyses. LFD provided the samples and clinical data. ARLA and EMR designed the experiments, 
interpreted data and reviewed the manuscript. All authors read and approved the final manuscript.

\section{Acknowledgements}

This study was supported by Fundação de Amparo a Pesquisa do Estado de São Paulo (FAPESP: Grant \#1998/14247-6) and Conselho Nacional de Desenvolvimento Científico e Tecnológico (CNPq: \#573754/2008-0). H.L. Gimenes-Teixeira and A.R. Lucena-Araujo received fellowships from CNPq and FAPESP (grants no. 150349/2011-4 and 07/55067-1, respectively).

\section{Author details}

${ }^{1}$ Department of Internal Medicine, Division of Hematology/Oncology, University of São Paulo, Ribeirão Preto, Brazil. ${ }^{2}$ Department of Genetics, Medical School of Ribeirão Preto and National Institute of Cell Based Therapy, University of São Paulo, Ribeirão Preto, Brazil. ${ }^{3}$ Medical School of Ribeirao Preto, University of São Paulo, Av. Bandeirantes, 3900, Ribeirao Preto, SP 14048-900, Brazil.

Received: 4 March 2013 Accepted: 4 April 2013

Published: 8 April 2013

\section{References}

1. Farag SS, VanDeusen JB, Fehniger TA, Caligiuri MA: Biology and clinical impact of human natural killer cells. Int J Hematol 2003, 78:7-17.

2. Kwong $Y L$, Anderson BO, Advani R, Kim WS, Levine AM, Lim ST: Management of T-cell and natural-killer-cell neoplasms in Asia: consensus statement from the Asian Oncology Summit 2009. Lancet Oncol 2009, 10:1093-1101.

3. Harabuchi Y, Takahara M, Kishibe K, Moriai S, Nagato T, Ishii H: Nasal natural killer (NK)/T-cell lymphoma: clinical, histological, virological, and genetic features. Int J Clin Oncol 2009, 14:181-190.

4. Dalmazzo LF, Jacomo RH, Marinato AF, Figueiredo-Pontes LL, Cunha RL, Garcia AB, et al: The presence of CD56/CD16 in T-cell acute lymphoblastic leukaemia correlates with the expression of cytotoxic molecules and is associated with worse response to treatment. $\mathrm{Br} J$ Haematol 2009, 144:223-229.

5. Montero I, Rios E, Parody R, Perez-Hurtado JM, Martin-Noya A, Rodriguez JM: CD56 in T-cell acute lymphoblastic leukaemia: a malignant transformation of an early myeloid-lymphoid progenitor? Haematologica 2003, 88:ELT26.

6. Sanchez MJ, Muench MO, Roncarolo MG, Lanier LL, Phillips JH: Identification of a common T/natural killer cell progenitor in human fetal thymus. J Exp Med 1994, 180:569-576.

7. Shibuya A, Nagayoshi K, Nakamura K, Nakauchi H: Lymphokine requirement for the generation of natural killer cells from CD34+ hematopoietic progenitor cells. Blood 1995, 85:3538-3546.

8. Kirigin FF, Lindstedt K, Sellars M, Ciofani M, Low SL, Jones $L$, et al: Dynamic microRNA gene transcription and processing during $T$ cell development. J Immunol 2012, 188:3257-3267.

9. Liu TY, Chen SU, Kuo SH, Cheng AL, Lin CW: E2A-positive gastric MALT lymphoma has weaker plasmacytoid infiltrates and stronger expression of the memory B-cell-associated miR-223: possible correlation with stage and treatment response. Mod Pathol 2010, 23:1507-1517.

10. Gantier MP: New perspectives in MicroRNA regulation of innate immunity. J Interferon Cytokine Res 2010, 30:283-289.

11. Danen-van Oorschot AA, Kuipers JE, Arentsen-Peters S, Schotte D, De Haas $\checkmark$, Trka J, et al: Differentially expressed miRNAs in cytogenetic and molecular subtypes of pediatric acute myeloid leukemia. Pediatr Blood Cancer 2012, 58:715-721.

12. Han BW, Feng DD, Li ZG, Luo XQ, Zhang $H$, Li XJ, et al: A set of miRNAs that involve in the pathways of drug resistance and leukemic stem-cell differentiation is associated with the risk of relapse and glucocorticoid response in childhood ALL. Hum Mol Genet 2011, 20:4903-4915.

13. Schotte D, De Menezes RX, Akbari MF, Khankahdani LM, Lange-Turenhout E, Chen $C_{\text {, et }}$ al: MicroRNA characterize genetic diversity and drug resistance in pediatric acute lymphoblastic leukemia. Haematologica 2011, 96:703-711.
14. Wang $P$, Gu Y, Zhang $Q$, Han $Y$, Hou J, Lin L, et al: Identification of resting and type I IFN-activated human NK cell miRNomes reveals microRNA378 and microRNA-30e as negative regulators of NK cell cytotoxicity. $\mathrm{J}$ Immunol 2012, 189:211-221.

15. Chiaretti S, Messina M, Tavolaro S, Zardo G, Elia L, Vitale A, et al: Gene expression profiling identifies a subset of adult T-cell acute lymphoblastic leukemia with myeloid-like gene features and over-expression of miR-223. Haematologica 2010, 95:1114-1121.

16. Mavrakis KJ, Van Der Meulen J, Wolfe AL, Liu X, Mets E, Taghon T, et al: A cooperative microRNA-tumor suppressor gene network in acute T-cell lymphoblastic leukemia (T-ALL). Nat Genet 2011, 43:673-678.

17. Santhekadur PK, Das SK, Gredler R, Chen D, Srivastava J, Robertson C, et al: Multifunction protein staphylococcal nuclease domain containing 1 (SND1) promotes tumor angiogenesis in human hepatocellular carcinoma through novel pathway that involves nuclear factor kappaB and miR-221. J Biol Chem 2012, 287:13952-13958.

18. Davis BN, Hilyard AC, Nguyen PH, Lagna G, Hata A: Induction of microRNA-221 by platelet-derived growth factor signaling is critical for modulation of vascular smooth muscle phenotype. J Biol Chem 2009, 284:3728-3738.

19. Yang J, Liu X, Nyland SB, Zhang R, Ryland LK, Broeg K, et al: Platelet-derived growth factor mediates survival of leukemic large granular lymphocytes via an autocrine regulatory pathway. Blood 2010, 115:51-60.

20. Huang X, Shen Q, Chen S, Chen S, Yang L, Weng J, et al: Gene expression profiles in BCL11B-siRNA treated malignant T cells. J Hematol Oncol 2011, 4:23.

21. Li L, Leid M, Rothenberg EV: An early T cell lineage commitment checkpoint dependent on the transcription factor Bcl11b. Science 2010, 329:89-93.

22. Li P, Burke S, Wang J, Chen X, Ortiz M, Lee SC, et al: Reprogramming of $\mathrm{T}$ cells to natural killer-like cells upon $\mathrm{Bcl} 11 \mathrm{~b}$ deletion. Science 2010, 329:85-89.

23. Huang X, Chen S, Shen Q, Yang L, Li B, Zhong L, et al: Analysis of the expression pattern of the BCL11B gene and its relatives in patients with T-cell acute lymphoblastic leukemia. J Hematol Oncol 2010, 3:44.

24. Oshiro A, Tagawa H, Ohshima K, Karube K, Uike N, Tashiro Y, et al: Identification of subtype-specific genomic alterations in aggressive adult T-cell leukemia/lymphoma. Blood 2006, 107:4500-4507.

25. Le Sage C, Nagel R, Agami R: Diverse ways to control p27Kip1 function: miRNAs come into play. Cell Cycle 2007, 6:2742-2749.

26. Pineau P, Volinia S, McJunkin K, Marchio A, Battiston C, Terris B, et al: miR221 overexpression contributes to liver tumorigenesis. Proc Natl Acad Sci US A 2010, 107:264-269.

27. Visone R, Russo L, Pallante P, De Martino I, Ferraro A, Leone V, et al: MicroRNAs (miR)-221 and miR-222, both overexpressed in human thyroid papillary carcinomas, regulate p27Kip1 protein levels and cell cycle. Endocr Relat Cancer 2007, 14:791-798.

28. Felicetti F, Errico MC, Bottero L, Segnalini P, Stoppacciaro A, Biffoni M, et al: The promyelocytic leukemia zinc finger-microRNA-221/-222 pathway controls melanoma progression through multiple oncogenic mechanisms. Cancer Res 2008, 68:2745-2754.

29. Fischer L, Gokbuget N, Schwartz S, Burmeister T, Rieder H, Bruggemann M, et al: CD56 expression in T-cell acute lymphoblastic leukemia is associated with non-thymic phenotype and resistance to induction therapy but no inferior survival after risk-adapted therapy. Haematologica 2009, 94:224-229.

30. Jaffe ES, Harris NL, Stein H, Campo E, Pileri SA, Swerdlow SW: Introduction and overview of the classification of the lymphoid neoplasms. In WHO Classification of Tumors of Haematopoietic and Lymphoid Tissues. 4th edition. Edited by Swerdlow SH, Elias C, Nancy Lee $H$, Jaffe ES, Pileri SA, Harald S, et al. Lyon: International Agency for Reasearch on Cancer (IARC); 2008:157-267.

31. Garcia-Manero G, Kantarjian HM: The hyper-CVAD regimen in adult acute lymphocytic leukemia. Hematol Oncol Clin North Am 2000, 14:1381-13xi.

32. Schrappe M, Reiter A, Ludwig WD, Harbott J, Zimmermann M, Hiddemann $W$, et al: Improved outcome in childhood acute lymphoblastic leukemia despite reduced use of anthracyclines and cranial radiotherapy: results 
of trial ALL-BFM 90. German-Austrian-Swiss ALL-BFM Study Group. Blood 2000, 95:3310-3322.

33. Scrideli CA, Assumpcao JG, Ganazza MA, Araujo M, Toledo SR, Lee ML, et al: A simplified minimal residual disease polymerase chain reaction method at early treatment points can stratify children with acute lymphoblastic leukemia into good and poor outcome groups. Haematologica 2009, 94:781-789.

doi:10.1186/2162-3619-2-10

Cite this article as: Gimenes-Teixeira et al:: Increased expression of miR221 is associated with shorter overall survival in T-cell acute lymphoid leukemia. Experimental Hematology \& Oncology 2013 2:10.

\section{Submit your next manuscript to BioMed Central and take full advantage of:}

- Convenient online submission

- Thorough peer review

- No space constraints or color figure charges

- Immediate publication on acceptance

- Inclusion in PubMed, CAS, Scopus and Google Scholar

- Research which is freely available for redistribution 